\title{
The Complex Toxicity of Tetracycline with Polystyrene Spheres on Gastric Cancer Cells
}

\author{
Xiemin Yan ${ }^{1}$, Yuanyuan Zhang ${ }^{2}$, Yuqin $\mathrm{Lu}^{3}$, Lei He ${ }^{3, *}$, Junhao Qu ${ }^{1,3}$, Chunxia Zhou ${ }^{1,2,4}$, \\ Pengzhi Hong ${ }^{1,2,4}$, Shengli Sun ${ }^{3}$, Hui Zhao ${ }^{3,4}$, Yanqiu Liang ${ }^{3}$, Lei Ren ${ }^{5} \oplus$, Yueqin Zhang ${ }^{5}$, \\ Jinjun Chen ${ }^{5}$ and Chengyong $\mathrm{Li}^{2,3,4, *(1)}$ \\ 1 College of Food Science and Technology, Guangdong Ocean University, Zhanjiang 524088, China; \\ xiemin_y@163.com (X.Y.); 15975997422@163.com (J.Q.); zhoucx@gdou.edu.cn (C.Z.); \\ hongpz@gdou.edu.cn (P.H.) \\ 2 Shenzhen Institute of Guangdong Ocean University, Shenzhen 518108, China; zyyla92@126.com \\ 3 School of Chemistry and Environment, Guangdong Ocean University, Zhanjiang 524088, China; \\ rebeccaaax@163.com (Y.L.); sunsl@gdou.edu.cn (S.S.); huizhao1978@163.com (H.Z.); \\ liangyanqiu11@126.com (Y.L.) \\ 4 Southern Marine Science and Engineering Guangdong Laboratory (Zhanjiang), Zhanjiang 524088, China \\ 5 College of Agriculture, Guangdong Ocean University, Zhanjiang 524088, China; renlei@gdou.edu.cn (L.R.); \\ yqzhang1982@163.com (Y.Z.); chenjj@gdou.edu.cn (J.C.) \\ * Correspondence: airyhelei@163.com (L.H.); cyli_ocean@163.com (C.L.); Tel.: +86-759-238-3636 (C.L.)
}

Received: 8 April 2020; Accepted: 16 April 2020; Published: 19 April 2020

\begin{abstract}
Nowadays, microplastics (MPs) exist widely in the marine. The surface has strong adsorption capacity for antibiotics in natural environments, and the cytotoxicity of complex are poorly understood. In the study, $500 \mathrm{~nm}$ polystyrene (PS-MPs) and $60 \mathrm{~nm}$ nanoplastics (PS-NPs) were synthesized. The adsorption of PS to tetracycline (TC) was studied and their toxicity to gastric cancer cells (AGS) was researched. The adsorption experimental results show that PS absorbing capacity increased with increasing TC concentrations. The defense mechanism results show that $60 \mathrm{~nm}$ PS-NPs, $500 \mathrm{~nm}$ PS-MPs and their complex induce different damage to AGS cells. Furthermore, $600 \mathrm{mg} / \mathrm{L}$ PS-NPs and PS-MPs decline cell viability, induce oxidation stress and cause apoptosis. There is more serious damage of $60 \mathrm{~nm}$ PS-NPs than $500 \mathrm{~nm}$ PS-MPs in cell viability and intracellular reactive oxygen species (ROS). DNA are also damaged by $60 \mathrm{~nm}$ PS-NPs and PS-TC NPs, $500 \mathrm{~nm}$ PS-MPs and PS-TC MPs, and $60 \mathrm{~nm}$ PS-NPs damage DNA more serious than $500 \mathrm{~nm}$ PS-MPs. Moreover, $60 \mathrm{~nm}$ PS-NPs and PS-TC NPs seem to promote bcl-2 associated X protein (Bax) overexpression. All treatments provided us with evidence on how PS-NPs, PS-MPs and their compounds damaged AGS cells.
\end{abstract}

Keywords: microplastics; nanoplastics; adsorption; tetracycline; AGS cells

\section{Introduction}

For many years, plastics have been applied in numerous fields, such as packing manufacture, cosmetics, clothing, and so on [1,2]. It is estimated that around 1.15 to 2.41 million tons of plastic waste were dumped into oceans annually [3]. Plastics have been found in hundreds of marine organism species [4-6]. Through Ultraviolet (UV) ray exposure and mechanical wear in the environment, plastics break down into small fragments. Particle diameters smaller $5 \mathrm{~mm}$ are defined as microplastics (MPs) [7-9]. MPs originate from two sources, including primary MPs and secondary MPs. Primary MPs are used as resin pellets in industry or as an ingredient in peelings and shower gels [10]. Secondary MPs are formed from larger plastic items degrading under favorable conditions. MPs smaller than $100 \mathrm{~nm}$ are defined as nanoplastics (NPs) [11]. In recent years, MPs have been deemed to be a 
new environmental pollutant through further investigation. Many researchers have found that a variety of aquatic species ingested MPs, including fish, oyster, and shrimp [12-14]. MPs damage their gastrointestinal tract and growth speed and enter their bodies [15-17]. The impact of MPs and NPs occur via many ways: their small size facilitates internalization by biota or pathogenic bacteria; and pollutants can absorb on to an MPs' surface $[18,19]$. Most significantly, MPs can enter the human body for resultant accumulation through the food chain [20-22]. Up to now, there are no obvious data to identify how MPs are hazardous to human health, but the alarm has been sounded.

Nowadays, antibiotics have attracted wide attention as a type of contaminant. Normally, antibiotics are rich in offshore breeding areas, which can enter the offshore environment through sewage discharge [23,24]. Moreover, antibiotics are applied in fisheries extensively, they also exacerbate residue in offshore water [25]. Tetracycline (TC), one of these antibiotics, is widely used to inhibit bacteria growth and kill pathogens. MPs have an extremely strong adsorption capacity on persistent organic pollutants [26-28]. What's more, MPs surface characteristics can be changed in the effect of physical and chemical function in the natural environment [29]. The adsorption capacity of MPs can be enhanced once an amino-group and carboxyl has formed on an MPs surface [30]. Some research found that the main interaction of polystyrene spheres (PS) and TC is electrostatic attraction, and as the existence of benzene, $\pi-\pi$ conjugation, polar interactions, and p-p interaction are also present [23,31]. In addition to individual pollution effects, their complex toxicity deserve more attention.

To study the toxicity of PS-MPs, PS-NPs and their combination with TC, gastric cancer cells (AGS) are chosen because they can be in contact with stomach cells first after consumption. In order to study whether nanoplastics can induce a greater negative effect to AGS cells than microplastics, both $500 \mathrm{~nm}$ PS-MPs and $60 \mathrm{~nm}$ PS-NPs were chosen according to the definition of microplastics and nanoplastics [32]. The toxicity of PS and PS compound TC (PS-TC) to AGS are determined by the basic experiments of cell viability, intracellular reactive oxygen species (ROS) and apoptosis. Comet assay aims to detect DNA damage. The aim is to provide a proof of how PS-MPs, PS-NPs and their compounds damage AGS cells. The study may provide a theoretical support for the negative effects of MPs on human health.

\section{Materials and Methods}

\subsection{Materials}

Styrene monomer and AIBN (2,2'-Azobis (2-methylpropionamide) dihydrochloride) were purchased from Shanghai Maclean Biochemical Technology Co., Ltd. (Shanghai, China). A three-necked bottle, rubber tube, and condensing return pipe were obtained in Zhanjiang Haibo Biotechnology Co., Ltd. (Zhanjiang, China). AGS cell line was acquired from Shanghai Institute of Biosciences Cell Resource Center, Chinese Academy of Sciences. Fetal bovine serum (FBS), trypsin, penicillin/streptomycin were supported by Guangzhou Zuoke Biotechnology Co., Ltd. (Guangzhou, China). The anti-Bax antibody was obtain from Santa Cruz Technology (Santa Cruz, CA, USA). And secondary antibodies used for western blot were purchased from Cell Signaling Technology (Danvers, MA, USA).

\subsection{Methods}

\subsubsection{Synthesis of PS-MPs and PS-NPs}

PS-MPs and PS-NPs were synthesized through monomer polymerization according to a previous described method [33,34]. Briefly, $500 \mathrm{~nm}$ (or $60 \mathrm{~nm}$ ) PS particles were synthesized in the following process: $90 \mathrm{~mL}$ (or $198 \mathrm{~mL}$ ) deionized water was added into three-necked bottle and warmed up to $55^{\circ} \mathrm{C}$ (or $90{ }^{\circ} \mathrm{C}$ ). After the reaction in the system, oxygen was taken away by nitrogen and $2,2^{\prime}$-Azobisisobutyronitrile (AIBN), as an initiator, was added into the system. The reaction lasted $10 \mathrm{~h}$ under nitrogen atmosphere and was cooled with $4{ }^{\circ} \mathrm{C}$ circulating water. After the reaction ended, the three-necked bottle was cooled with ice-cold water to room temperature. $500 \mathrm{~nm}$ PS-MPs was 
cleaned using absolute ethanol through $0.22 \mu \mathrm{m}$ microporous membrane. As for $60 \mathrm{~nm}$ PS-NPs, all solutions were loaded into a $30 \mathrm{kDa}$ dialysis bag, and the bags were put into deionized water for 5 days, and deionized water was changed every day. Finally, all samples were dried at $50{ }^{\circ} \mathrm{C}$.

\subsubsection{Adsorption Experiments}

According to the study by Hans et al. [35], TC has a ultraviolet spectrophotometer (UV-V) response signal. The UV-V absorption peak of TC was determined at $341 \mathrm{~nm}$. The linear range was ascertained. The sorption capacity of TC on PS-NPs and PS-MPs were researched by batch experiments. TC concentrations were 1, 5, 10, 50, and $100 \mathrm{mg} / \mathrm{L}$ in the study. Next, $1 \mathrm{~g} / \mathrm{L}$ PS-NPs and PS-MPs were uniformly dispersed to various TC concentration solutions by ultrasound, respectively. All samples were mixed uniformly in $300 \mathrm{rpm}$ with magnetic stirring. Samples were collected after removing PS-NPs or PS-MPs every hour and $500 \mathrm{~nm}$ PS-MPs samples were obtained by filtering $0.22 \mu \mathrm{m}$ microporous membrane. For $60 \mathrm{~nm}$ PS-NPs samples, solutions were acquired through $0.02 \mu \mathrm{m}$ aluminum oxide membrane to remove PS-NPs. The absorbance values of all samples $(1,2,3,4,5,6 \mathrm{~h})$ were measured using UV-V (U-3900H, HITACHI) at $341 \mathrm{~nm}$.

\subsubsection{Cell Viability Assay}

AGS cells cultured in F-12K medium supplemented with $10 \% \mathrm{FBS}, 1 \%$ penicillin/streptomycin solution, and $5 \% \mathrm{CO}_{2}$ at $37^{\circ} \mathrm{C}$ incubator. A $200 \mu \mathrm{L}$ AGS cell suspension $\left(1 \times 10^{5}-5 \times 10^{5}\right.$ cells $\left./ \mathrm{mL}\right)$ was spread into 48-well plates overnight. Cell viability was measured using an MTS assay kit (Nan Jing Jian Cheng Biotechnology Co., Ltd. Nanjing, China) after exposure to PS-NPs and PS-MPs for 24 h. Absorbance of the mixture was measured at $570 \mathrm{~nm}$ using a microplate reader (Synergy H1, BioTek, VT, USA). Cell viability was calculated by comparing with the absorbance of the control group.

\subsubsection{Intracellular ROS Analysis}

AGS intracellular ROS levels induced by PS-NPs, PS-MPs (50, 100, 200, 400, $600 \mathrm{mg} / \mathrm{L})$, and TC $(0.5,1,5,10,20 \mathrm{mg} / \mathrm{L})$ exposure were detected by a ROS assay kit (DCFH-DA, Beyotime Biotechnology, Shanghai, China). Next, $10 \mathrm{mM}$ DCFH-DA was added to each well of 96-well plate after exposure to PS-NPs, PS-MPs, and TC for $24 \mathrm{~h}$. After incubating under $37^{\circ} \mathrm{C}$ for $30 \mathrm{~min}$, AGS cells were washed with PBS. The fluorescence of DCF was detected in the excitation/emission wavelengths of $488 / 525 \mathrm{~nm}$ using an Olympus fluorescence microscope. The normalized DCF fluorescence values of exposed groups were calculated by comparing them with the control group using Image J.

\subsubsection{Apoptosis Experiment}

AGS cells $\left(2 \times 10^{5}-5 \times 10^{5}\right.$ cells/mL) were exposed to PS-NPs, PS-MPs, PS-TC NPs, MPs (50, 100, 200, 400, $600 \mathrm{mg} / \mathrm{L})$, and TC $(0.5,1,5,10,20 \mathrm{mg} / \mathrm{L})$ for $24 \mathrm{~h}$. Then all cells were stained with Annexin V-FITC/PI apoptosis kit (Beyotime Biotechnology, Shanghai, China). According to the manufacturer's instructions, all groups were pictured by an Olympus fluorescence microscope.

\subsubsection{Comet Experiment}

All treatment cells were collected using trypsinization, and cell suspension concentration was adjusted to $1 \times 10^{5}$ cells $/ \mathrm{mL}$ with PBS. The slides were coated with $0.5 \%$ normal-melting-point agarose as a first layer. After solidification, $0.5 \%$ low-melting-point agarose $(80 \mu \mathrm{L})$ and cell suspension $\left(1 \times 10^{5}\right.$ cells/mL, $\left.20 \mu \mathrm{L}\right)$ was poured and mixed on the first layer. Once the agarose coagulated, all samples were put in lysis solution for $2 \mathrm{~h}$. Next, they were transferred to alkaline electrophoresis solution (AES) for $30 \mathrm{~min}$. After the DNA double helical structure was unwound, the electrophoresis was performed at $25 \mathrm{~V}$ for $30 \mathrm{~min}$ in AES buffer and then neutralized with Tris- $\mathrm{HCl}$ buffer $(0.1 \mathrm{mM}$, $\mathrm{pH}=13$ ). All bands were dehydrated using absolute ethanol and dried, stained bands were gathered and analyzed. 


\subsubsection{Analysis of Apoptotic Protein by Western Blot}

In order to further research PS-MPs and PS-NPs toxicity, Bax as an apoptotic protein was detected. Six hundred milligrams per liter PS-MPs and PS-NPs co-cultured with AGS cells for $24 \mathrm{~h}$. Next, AGS cells in 6-well plate were washed using PBS, then $60 \mu \mathrm{L}$ cell lysates with PMSF $(1 \mathrm{mM})$ was added lasted for $30 \mathrm{~min}$ on ice. Total proteins were quantified using a BCA protein assay kit (Beyotime Biotechnology, Shanghai, China) and $20 \mu \mathrm{g}$ protein was separated electrophoretically using a $10 \%$ sodium dodecyl sulfate-polyacrylamide gel electrophoresis (SDS-PAGE). All bands were transferred to polyvinylidene fluoride (PVDF) using a wit transfer method. Bands were blocked with $5 \%$ skim milk for $2 \mathrm{~h}$, and incubated with primary antibodies at $4{ }^{\circ} \mathrm{C}$ overnight. The next day, a secondary antibody was incubated for $2 \mathrm{~h}$ at room temperature. All bands were visualized with an enhanced chemiluminescence (ECL) kit (Beyotime Biotechnology, Shanghai, China).

\section{Results}

\subsection{The Principle of the Study}

The mechanism is shown in Figure 1. Sixty nanometers PS-NPs and $500 \mathrm{~nm}$ PS-MPs were synthesized by monomer polymerization. The bath sorption experiment was treated as following: $1 \mathrm{~g} / \mathrm{L}$ PS-NPs and PS-MPs are mixed with a different concentration of TC $(1,5,10,50,100 \mathrm{mg} / \mathrm{L})$, respectively. PS-MPs and PS-NPs are removed through a filter every hour. The concentration of TC remaining in solution can be determined according to a liner curve. PS-MPs and PS-NPs co-culture with AGS cells. Cell viability, oxidative stress, and apoptosis as the indicators of cell damage are detected. Comet experiment results confirmed the toxicity in the level of DNA.

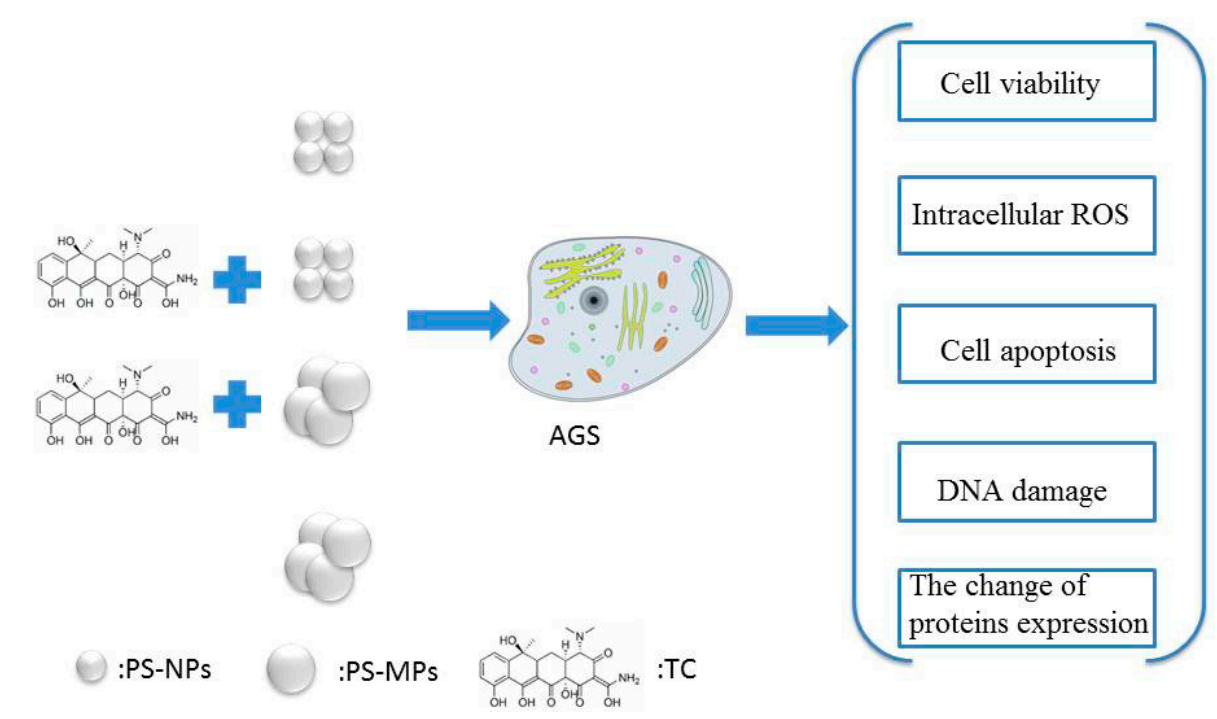

Figure 1. The experimental schematic. Abbreviations including Tetracycline (TC), polystyrene microplastics (PS-MPs) and polystyrene nanoplastics (PS-NPs).

\subsection{The Characteristic of PS Particles}

In order to confirm PS-NPs and PS-MPs were obtained according to the previous research method [34], the sizes of PS-NPs and PS-MPs as depicted in Figure 2a,c were evaluated by SEM. Considering the interaction between PS and medium, the sizes of PS in medium are also measured as described in Figure 2b,d. The results suggest that both $60 \mathrm{~nm}$ PS-NPs and $500 \mathrm{~nm}$ PS-MPs surface adsorb some proteins. What is more, previous study has identified that MPs' surface formed corona in medium [36]. Besides, the compound of PS-TC is identified with Fourier transform infrared spectroscopy (FTIR) in Figure 2e. The hydration radius of PS-NPs and PS-MPs are determined at Table 1 . The results identify PS particles in medium that are larger than in deionized water. PS sizes 
become larger after exposure to medium for $24 \mathrm{~h}$ because their surface attaches some proteins or protein fragments.
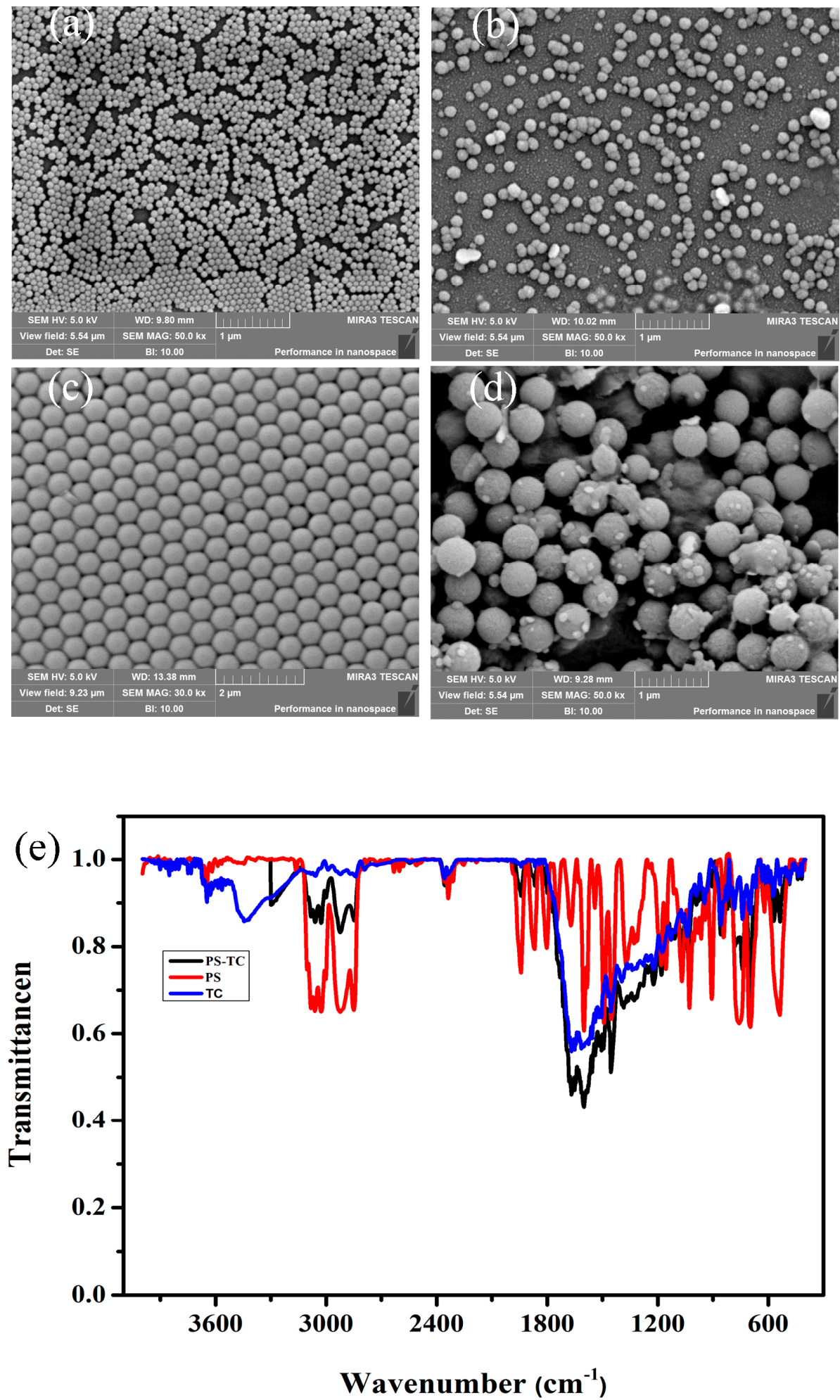

Figure 2. The characteristics of polystyrene spheres (PS). (a) $60 \mathrm{~nm}$ PS-NPs; (b) $60 \mathrm{~nm}$ PS-NPs in medium; (c) 500 nm PS-MPs; (d) 500 nm PS-MPs in medium; (e) Fourier transform infrared spectroscopy of PS and PS compound TC (PS-TC). 
Table 1. The hydrated sizes of PS-NPs and PS-MPs.

\begin{tabular}{cc}
\hline Groups & Average Size (nm) \\
\hline 60 nm PS-NPs & $155.64 \pm 48.97$ \\
60 nm PS-NPs in medium & $354.25 \pm 151.93$ \\
500 nm PS-MPs & $685.43 \pm 35.71$ \\
500 nm PS-MPs in medium & $873.02 \pm 27.70$ \\
\hline
\end{tabular}

\subsection{Adsorption Experiment}

In Figure 3a, it is clear that TC has strong UV-vis adsorption at $341 \mathrm{~nm}$. There is a good linearity ranging from $0.5-50 \mathrm{mg} / \mathrm{L}$ in Figure $3 \mathrm{~b}$. As shown in Figure $3 \mathrm{c}, \mathrm{d}$, with TC concentrations increasing, both $500 \mathrm{~nm}$ PS-MPs and $60 \mathrm{~nm}$ PS-NPs have an increasing adsorption capacity on TC. A $500 \mathrm{~nm}$ PS-MP adsorption quantity is $0.66,0.94,2.61,4.75,6.60 \mathrm{mg} / \mathrm{g}$ in $6 \mathrm{~h}$, respectively, and the adsorption quantity of $60 \mathrm{~nm}$ PS-NPs is $0.43,3.92,4.39,10.74,20.20 \mathrm{mg} / \mathrm{g}$ in $6 \mathrm{~h}$, respectively. In general, particle sizes have a great influence on the sorption behavior of MPs, and $500 \mathrm{~nm}$ PS-MPs and $60 \mathrm{~nm}$ PS-NPs have an obvious difference in the study. The results suggest that $60 \mathrm{~nm}$ PS-NPs have a stronger sorption of TC than $500 \mathrm{~nm}$ PS-MPs.
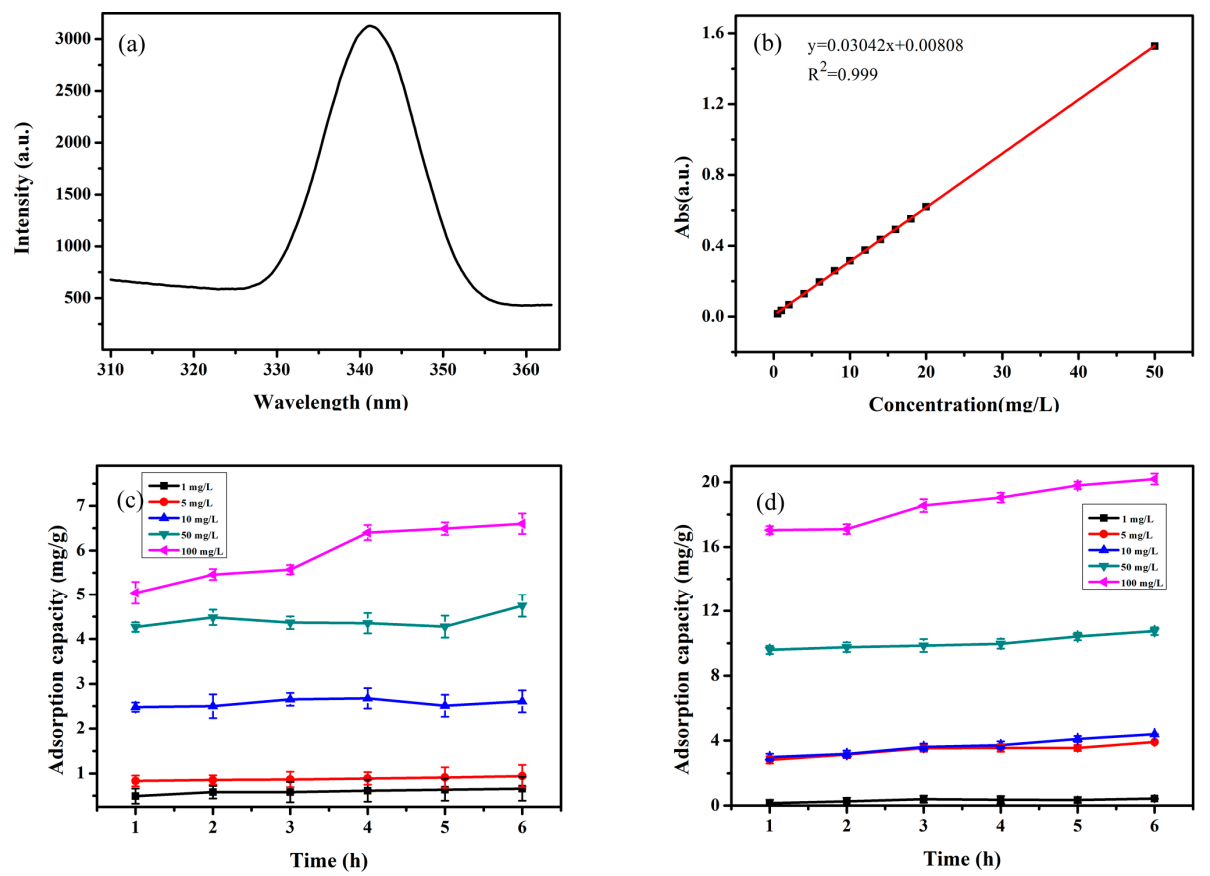

Figure 3. Adsorption experiments. (a) The UV adsorption of TC; (b) The linear range of TC; (c) The adsorption capacity of $500 \mathrm{~nm}$ PS-MPs to TC (1, 5, 10, 50, $100 \mathrm{mg} / \mathrm{L})$; (d) The adsorption capacity of $60 \mathrm{~nm}$ PS-NPs to TC $(1,5,10,50,100 \mathrm{mg} / \mathrm{L})$.

\subsection{Cell Viability Assay}

In Figure 4a, AGS cell viability decreases to 80 percent with $600 \mathrm{mg} / \mathrm{L} 500 \mathrm{~nm}$ PS-MPs exposure for $24 \mathrm{~h}$. There is no obvious toxicity under $400 \mathrm{mg} / \mathrm{L} 500 \mathrm{~nm}$ PS exposure. As shown in Figure 4b, AGS cell viability decreases to 80 percent with an PS-TC NPs concentration between $400 \mathrm{mg} / \mathrm{L}$ and $600 \mathrm{mg} / \mathrm{L}$. In Figure 4e, $20 \mathrm{mg} / \mathrm{L}$ TC there is clearly decreased cell viability. In Figure 4d, AGS cell viability has an apparently declining co-culture with $60 \mathrm{~nm}$ PS-NPs $(400,600,800 \mathrm{mg} / \mathrm{L})$ rather than $500 \mathrm{~nm}$ PS-MPs. What's more, cell viability has no large diversity among 400, 600, $800 \mathrm{mg} / \mathrm{L}$. PS-NPs. As shown in Figure 4f, $60 \mathrm{~nm}$ PS-TC NPs have induced the biggest lethal effect compared to $60 \mathrm{~nm}$ PS-NPs and $500 \mathrm{~nm}$ PS-TC NPs. These results indicate that a high concentration of PS has a low toxicity. However, the damage mechanism of PS-NPs and PS-MPs need to be analyzed from more dates. 

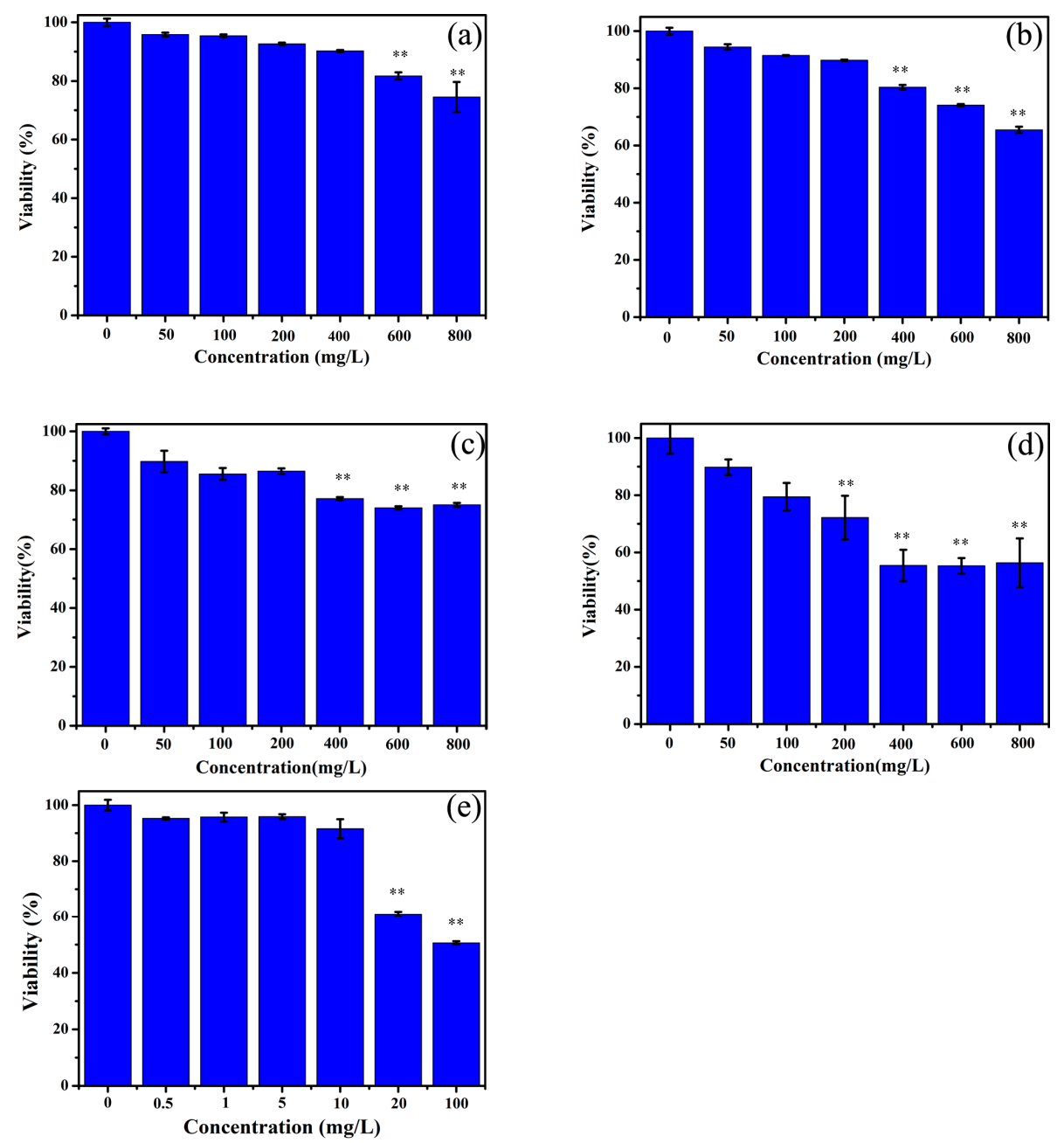

Figure 4. Cell viability assay. (a) Cell viability of exposing $500 \mathrm{~nm}$ PS-MPs (50, 100, 200, 400, 600, $800 \mathrm{mg} / \mathrm{L}$ ); (b) Cell viability of exposing $500 \mathrm{~nm}$ PS-TC MPs (50, 100, 200, 400, 600, $800 \mathrm{mg} / \mathrm{L}$ ); (c) Cell viability of exposing $60 \mathrm{~nm}$ PS-NPs (50, 100, 200, 400, 600, $800 \mathrm{mg} / \mathrm{L})$; (d) Cell viability of exposing $60 \mathrm{~nm}$ PS-TC NPs $(50,100,200,400,600,800 \mathrm{mg} / \mathrm{L})$; (e) Cell viability of exposing TC $(0.5,1,5,10,20$, $100 \mathrm{mg} / \mathrm{L}) ;(* *: p<0.01)$.

\subsection{Intracellular ROS}

In this study, intracellular ROS levels are detected using an inverted Olympus fluorescence microscope. As shown in Figure 5, intracellular ROS levels are induced by PS and ROS levels have an increasing trend with increasing PS concentrations. It is obvious that oxidative stress has been triggered in Figure 5a,b, while AGS cells are exposed with 400 and $600 \mathrm{mg} / \mathrm{L} 500 \mathrm{~nm}$ PS-MPs and PS-TC MPs. What is more, in Figure 5c,d, 50, 100, 200, 400, $600 \mathrm{mg} / \mathrm{L} 60 \mathrm{~nm}$ PS-NPs and PS-TC NPs induce intracellular ROS apparently increasing compared with the control. As shown in Figure $5 \mathrm{f}$, the fluorescence intensity of all exposure groups is analyzed using Image J. There is a significant difference between $500 \mathrm{~nm}$ PS-MPs and $60 \mathrm{~nm}$ PS-NPs in Figure 5f. The same result is determined between $500 \mathrm{~nm}$ PS-TC MPs and $60 \mathrm{~nm}$ PS-TC NPs. The results prove that $60 \mathrm{~nm}$ PS-NPs have a more significant effect on AGS cells than 500 nm PS-MPs. 
(a)
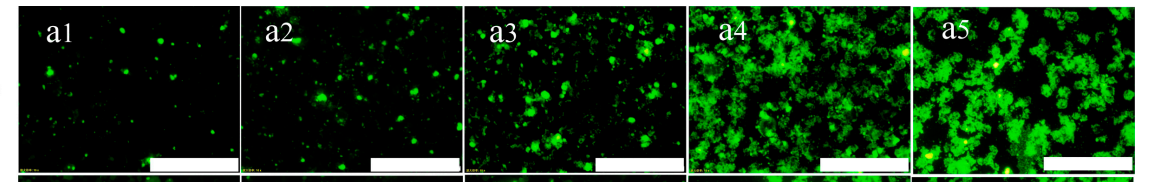

(b)
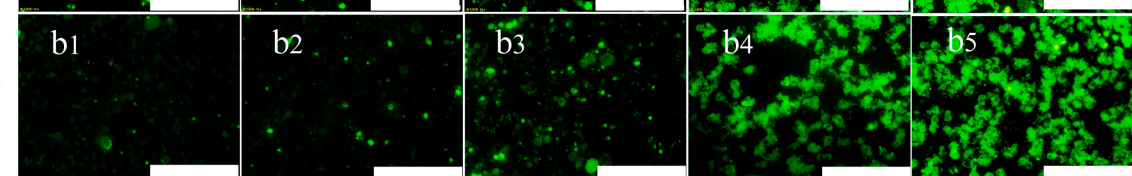

(c)
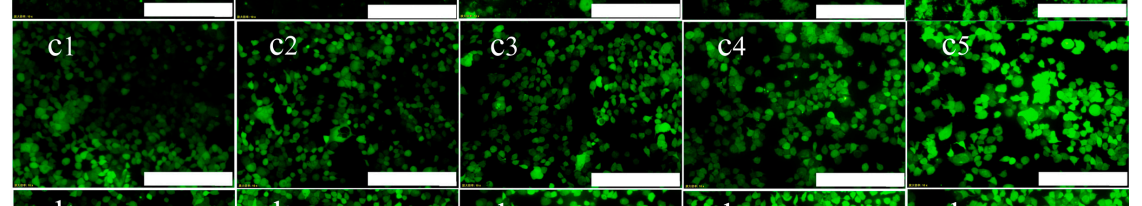

(d)

(e)
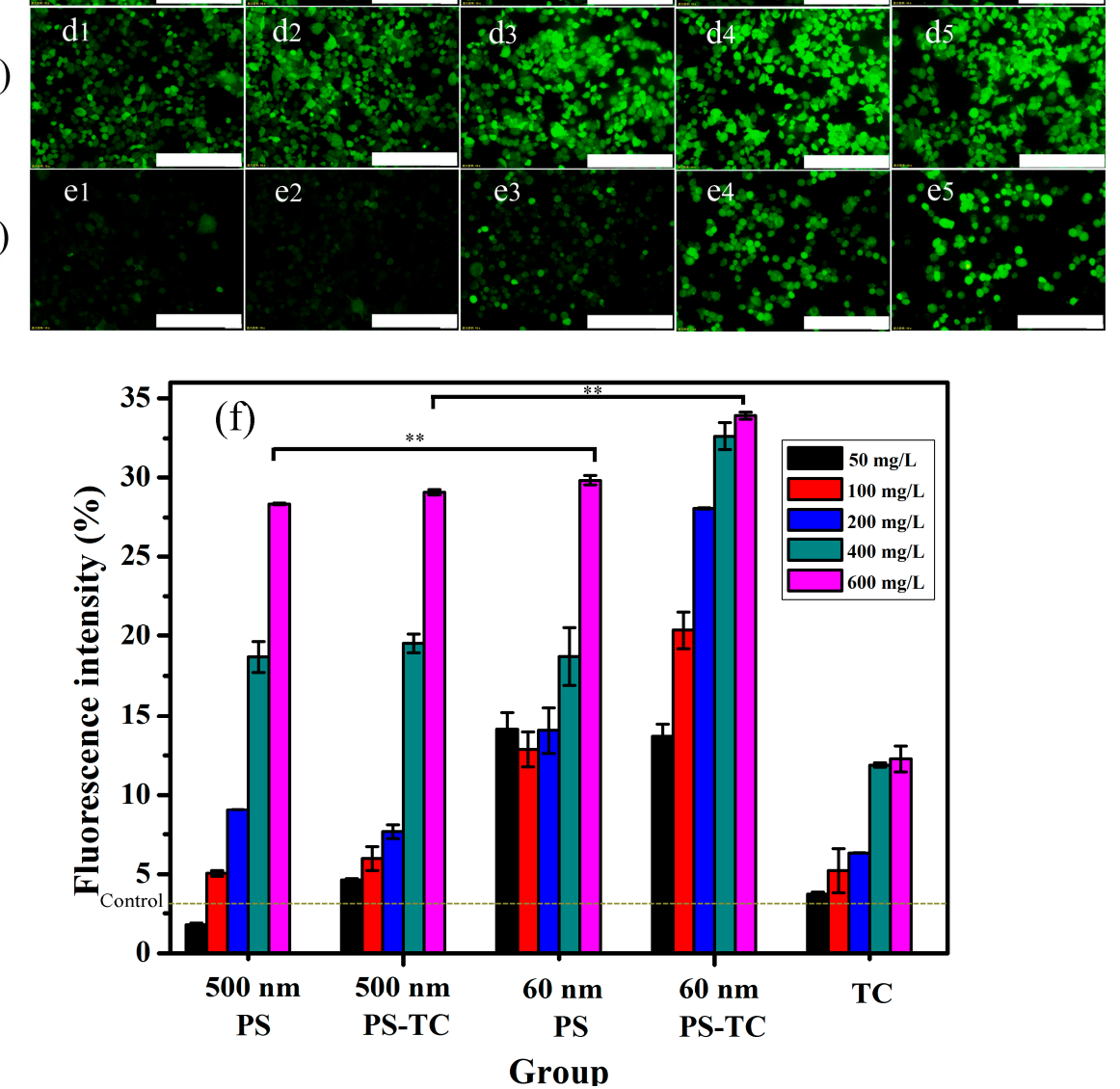

Figure 5. Fluorescence images and intensity of AGS cells. (a) Fluorescence images of exposing $500 \mathrm{~nm}$ PS-MPs (50, 100, 200, 400, 600 mg/L); (b) Fluorescence images of exposing $500 \mathrm{~nm}$ PS-TC MPs (50, 100, 200, 400, $600 \mathrm{mg} / \mathrm{L}$ ); (c) Fluorescence images of exposing $60 \mathrm{~nm}$ PS-NPs (50, 100, 200, 400, $600 \mathrm{mg} / \mathrm{L}$ ); (d) Fluorescence images of exposing $60 \mathrm{~nm}$ PS-TC NPs (50, 100, 200, 400, $600 \mathrm{mg} / \mathrm{L}$ ); (e) Fluorescence images of exposing TC (0.5, 1, 5, 10, $20 \mathrm{mg} / \mathrm{L})$; (f) Proportion of fluorescence intensity in Figure 5a-e; (scale: $\left.250 \mu \mathrm{m} ;{ }^{* *}: p<0.01\right)$.

\subsection{Apoptosis Experiment}

In Figure 6, it is apparent that nuclei are stained with red. The result proves that PS-NPs and PS-MPs induce AGS apoptosis. Because there is no obviously green fluorescence in Figure 6, which is the symbol of early apoptosis, it can be concluded that PS-NPs and PS-MPs did not induce early apoptosis of AGS cells. As shown in Figure $6 \mathrm{a}-\mathrm{d}$, the number of AGS cell apoptosis significantly increases as PS-NPs and PS-MPs concentrations increase. In particular, $500 \mathrm{~nm}$ PS-TC MPs induce AGS apoptosis easier than $500 \mathrm{~nm}$ PS-MPs at the same concentration. As shown in Figure $6 \mathrm{c}, \mathrm{d}$, the results suggest that $60 \mathrm{~nm}$ PS-NPs and PS-TC NPs also induce AGS apoptosis, but there is little diversity 
between $60 \mathrm{~nm}$ PS-NPs and PS-TC NPs. In Figure $6 \mathrm{e}, 10$ and $20 \mathrm{mg} / \mathrm{L}$ TC also induce AGS cell apoptosis. Therefore, it can be concluded that PS-MPs, PS-NPs, and TC in high concentrations can induce AGS cells apoptosis.

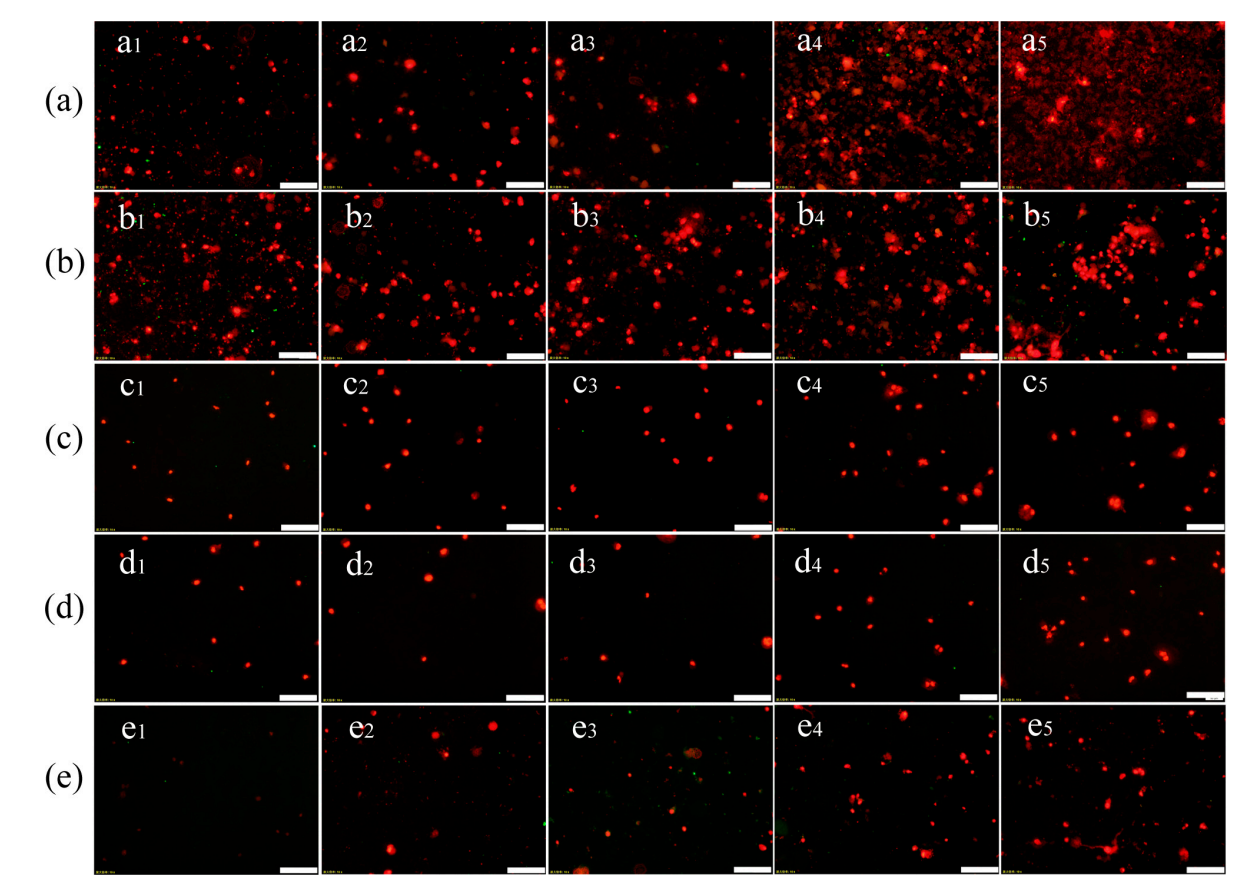

Figure 6. Fluorescence images of AGS cell apoptosis and fluorescence intensity. (a) Fluorescence images of exposing $500 \mathrm{~nm}$ PS-MPs (50, 100, 200, 400, $600 \mathrm{mg} / \mathrm{L}$ ); (b) Fluorescence images of exposing $500 \mathrm{~nm}$ PS-TC MPs (50, 100, 200, 400, $600 \mathrm{mg} / \mathrm{L})$; (c) Fluorescence images of exposing $60 \mathrm{~nm}$ PS-TC NPs (50, 100, 200, 400, $600 \mathrm{mg} / \mathrm{L}$ ); (d) Fluorescence images of exposing $60 \mathrm{~nm}$ PS-NPs (50, 100, 200, 400, $600 \mathrm{mg} / \mathrm{L}$ ); (e) Fluorescence images of exposing TC $(0.5,1,5,10,20 \mathrm{mg} / \mathrm{L})$; (scale: $250 \mu \mathrm{m})$.

\subsection{Comet Experiment Results}

In Figure 7, there is an obvious tail among all exposure groups via the electrophoresis. Tail lengths of all exposure groups are longer compared with the control in Figure 7a. As shown in Figure 7b,c, the data demonstrates that both $600 \mathrm{mg} / \mathrm{L} 500 \mathrm{~nm}$ PS-MPs and PS-TC MPs have induced a certain amount of tail. Tail length has a little diversity between $500 \mathrm{~nm}$ PS-MPs and PS-TC MPs in Figure 7g. Both groups cause AGS cell DNA damaged in some way. Similarly, it is noteworthy that the cell tail is longer in Figure 7d,e. In detail, tail length of $600 \mathrm{mg} / \mathrm{L} 60 \mathrm{~nm}$ PS-TC NPs is three times that of the $500 \mathrm{~nm}$ PS-TC MPs exposure group in Figure 7g, and $60 \mathrm{~nm}$ PS-TC NPs induce significantly more damage to AGS than PS-NPs. It also determines that $20 \mathrm{mg} / \mathrm{L}$ TC also damaged AGS DNA seriously in Figure 7f. The results provide the evidence that PS-MPs can cause cellular damage at the genetic level. This damage could cause other physical or chemical injuries to AGS cells. 

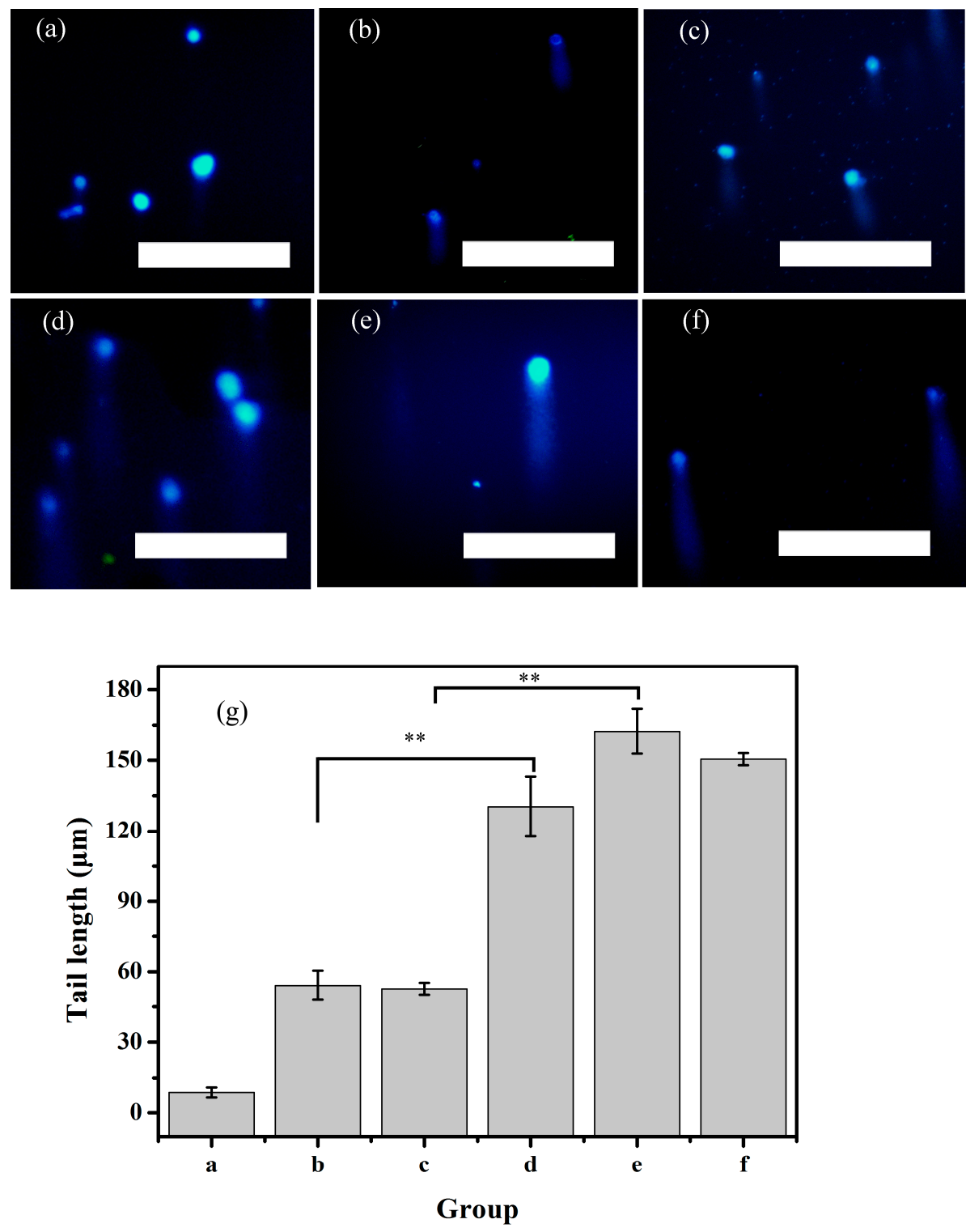

Figure 7. Comet assay. (a) Control; (b) 600 mg/L 500 nm PS-MPs; (c) 600 mg/L 500 nm PS-TC MPs; (d) $600 \mathrm{mg} / \mathrm{L} 60 \mathrm{~nm}$ PS-NPs; (e) $600 \mathrm{mg} / \mathrm{L} 60 \mathrm{~nm}$ PS-TC NPs; (f) $20 \mathrm{mg} / \mathrm{L} \mathrm{TC}$; (g) The tail length of Figure 7a-f; (scale: $250 \mu \mathrm{m}$; ${ }^{* *}: p<0.01$ ).

\subsection{Apoptotic Protein Expression}

In Figure 8, it is apparent that the gray values are higher in $60 \mathrm{~nm}$ PS-NPs and $60 \mathrm{~nm}$ PS-TC NPs than in the control. Both of them promote Bax overexpression and induce AGS apoptosis. However, $500 \mathrm{~nm}$ PS-MPs and $500 \mathrm{~nm}$ PS-TC MPs do not obviously promote apoptosis. The reason for this may be that NPs are smaller and enter AGS cells easily for $24 \mathrm{~h}$ acute exposure, meaning that $500 \mathrm{~nm}$ PS-MP may adsorb lots of protein in medium and their sizes are bigger than $500 \mathrm{~nm}$. It is difficult to go through cell member. Therefore, PS-NPs promote AGS apoptotic easier than PS-MPs. This proves that NPs induce more damage to AGS than MPs. 


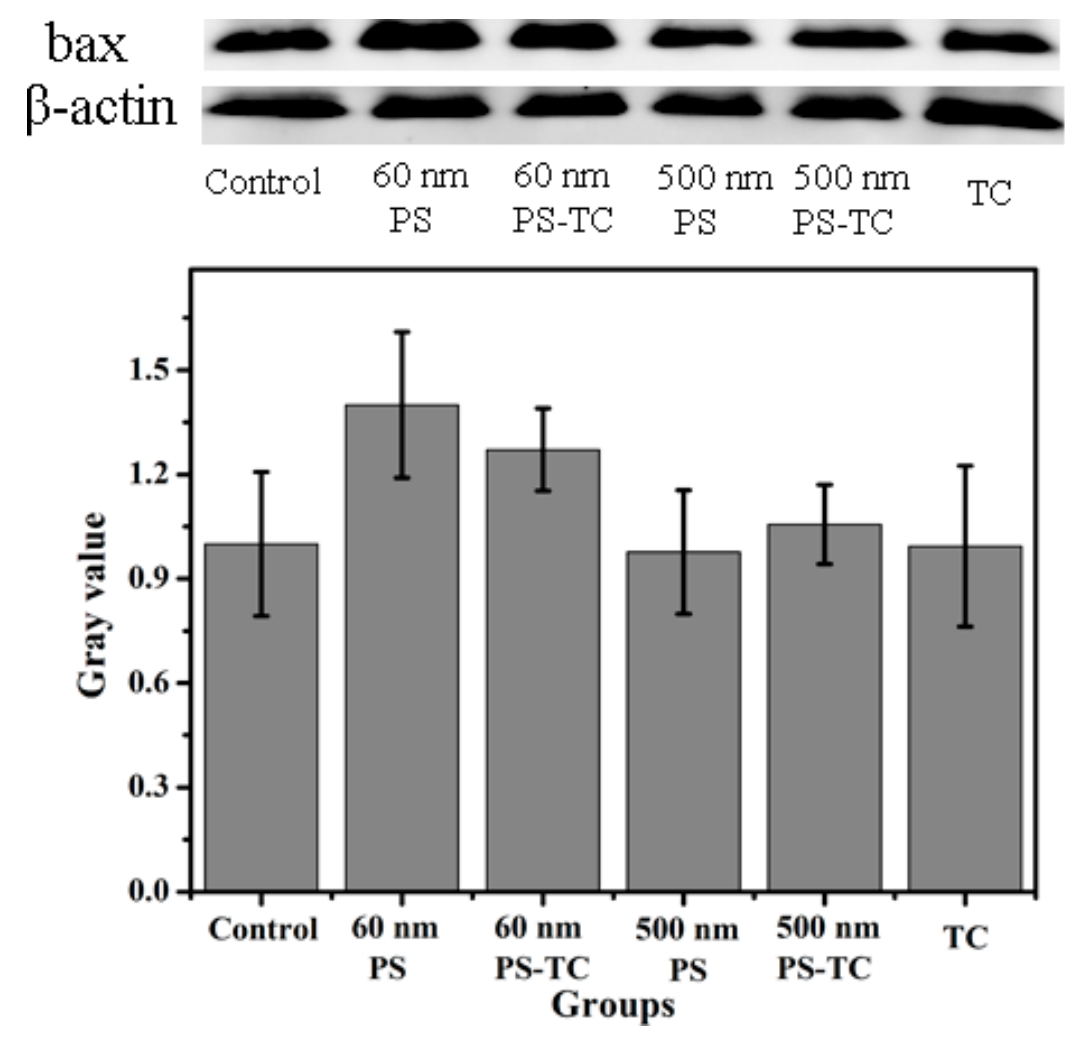

Figure 8. Apoptosis protein expression. The expression level of Bax protein in all groups (60 nm PS-NPs, 60 nm PS-TC NPs, 500 nm PS-MPs, 500 nm PS-TC MPs, TC).

\section{Discussion}

According to an investigation [37], PS particles have a considerably different adsorption to antibiotics because of their different functional groups. The adsorption capacity is positively related to TC concentrations. In the study, the hydration diameters of PS-NPs and PS-MPs in medium are larger in water because their surfaces absorb a level substance. We infer that PS-NPs' and PS-MPs' surfaces may combine with proteins or protein fragments in medium. Some researchers found that MPs can interact with digestive tract cells and NPs can go through the digestive tract [38-40]. The major adverse effects on organisms may be caused by MPs, NPs, and complex. Therefore, in order to study the adverse effects of $60 \mathrm{~nm}$ PS-NPs, $500 \mathrm{~nm}$ PS-MPs and PS-TC on humans, AGS cells are selected in this case. The research results suggest that $60 \mathrm{~nm}$ PS-NPs and $500 \mathrm{~nm}$ PS-MPs below $400 \mathrm{mg} / \mathrm{L}$ do not decrease cell viability obviously, which indicates a low cytotoxicity of PS-NPs and PS-MPs. Intracellular ROS levels and apoptosis are analyzed as two basic cytotoxicity functions. A study has confirmed that ROS levels might be different due to the various experimental conditions and species [41]. The results show that 200, 400, $600 \mathrm{mg} / \mathrm{L} 60 \mathrm{~nm}$ PS-NPs and PS-TC NPs inducing intracellular ROS increased significantly, and 400, $600 \mathrm{mg} / \mathrm{L} 500 \mathrm{~nm}$ PS-MPs and PS-TC MPs also induce and increase in intracellular ROS levels. Besides, the apoptotic results indicate that $600 \mathrm{mg} / \mathrm{L}$ PS-MPs, PS-TC MPs induce AGS apoptosis. Both $600 \mathrm{mg} / \mathrm{L} 60 \mathrm{~nm}$ PS-NPs and PS-TC NPs as well as $20 \mathrm{mg} / \mathrm{L}$ TC have some influence on AGS cell apoptosis. The results suggest that high concentrations of PS-NPs and PS-MPs can induce AGS apoptosis easier, but there is no obvious effect at a low concentration. It is reasonable to assume that protein coronas formed on the surface of PS-NPs and PS-MPs according to the previous study [42]. Protein coronas consist of biomolecules, proteins, and protein fragments. The forming of protein coronas may be due to chemical bonding and hydrogen bond interaction [42]. Their cytotoxicity may be weakened because protein coronas prevent PS-NPs and PS-MPs interacting with AGS directly.

Furthermore, both an endogenous and exogenous damage factor can induce DNA chain break. Comet results show that $600 \mathrm{mg} / \mathrm{L} 60 \mathrm{~nm}$ PS-NPs or PS-TC NPs damage DNA seriously compared 
with control, $600 \mathrm{mg} / \mathrm{L} 500 \mathrm{~nm}$ PS-MPs or PS-TC MPs. It proves that PS-NPs cause DNA damage more seriously than PS-MPs. The results seem to suggest that PS-NPs can go through cell membranes easily and cause genotoxicity. The above results provide insights into the different toxicities of $60 \mathrm{~nm}$ PS-NPs and $500 \mathrm{~nm}$ PS-MPs in AGS cells, and these data are very useful for human risk assessment.

\section{Conclusions}

In the study, adsorption experiment results demonstrate that $60 \mathrm{~nm}$ PS-NPs and $500 \mathrm{~nm}$ PS-MPs have an increased adsorption capacity to TC with the incensement of TC concentrations $(1,5,10,50$, $100 \mathrm{mg} / \mathrm{L}$ ) and that $60 \mathrm{~nm}$ PS-NPs and $500 \mathrm{~nm}$ PS-MPs can induce AGS cell damage. Furthermore, $600 \mathrm{mg} / \mathrm{L}$ PS-NPs and PS-MPs reduce cell viability, stimulate oxidation stress, and apoptosis. Sixty nanometer PS-NPs induce more serious damage than $500 \mathrm{~nm}$ PS-MPs in cell viability and intracellular ROS. DNA are also damaged by $60 \mathrm{~nm}$ PS-NPs and PS-TC NPs, $500 \mathrm{~nm}$ PS-MPs, and PS-TC MPs. What is more, $60 \mathrm{~nm}$ PS-NPs damages DNA more serious than $500 \mathrm{~nm}$ PS-MPs and $60 \mathrm{~nm}$ PS-NPs promote AGS apoptosis easier than $500 \mathrm{~nm}$ PS-MPs. All results show that oxidative stress and apoptosis-related signaling pathways may be activated. The study results provide evidence that PS-NPs and PS-MPs compound with TC, causing AGS cell damage under 24 h exposure.

Author Contributions: Conceptualization, S.S. and H.Z.; methodology, L.H. and Y.Z.; software, Y.L. (Yuqin Lu); validation, C.Z., C.L., and X.Y.; formal analysis, P.H.; investigation, J.Q.; data curation, Y.Z. (Yuanyuan Zhang); writing-original draft preparation, X.Y.; writing-review and editing, C.L.; visualization, J.C.; supervision, Y.L. (Yanqiu Liang); project administration, L.R.; funding acquisition, C.L. All authors have read and agreed to the published version of the manuscript.

Funding: This research was funded by Guangdong Yangfan Program (201635018), Guangdong Special Support Program (2017TQ04N706), Science and Technology Planning Project of Zhanjiang City (2018A02014), Guangdong MEPP Fund (No. GDOE2019A52, R\&D on Degradation of DL-PCBs and Microplastics Exposure to Microbes in South China Sea (Zhanjiang)), Industrial Development Special Funds of Dapeng New Area (KY20180202), Southern Marine Science and Engineering Guangdong Laboratory (Zhanjiang) (ZJW-2019-07, ZJW-2019-08), Innovation and Development Project about Marine Economy Demonstration of Zhanjiang City (2017C8B1), the Graduate Education Innovation Planning Project of Guangdong Ocean University (201924) and Training Programs of Innovation and Entrepreneurship for Undergraduates (CXXL2018008, CXXL2019302).

Conflicts of Interest: The authors declare no conflict of interest.

\section{References}

1. Carbery, M.; O'Connor, W.; Palanisami, T. Trophic transfer of microplastics and mixed contaminants in the marine food web and implications for human health. Environ. Int. 2018, 115, 400-409. [CrossRef] [PubMed]

2. Lavers, J.L.; Bond, A.L. Exceptional and rapid accumulation of anthropogenic debris on one of the world's most remote and pristine islands. Proc. Natl. Acad. Sci. USA 2017, 114, 6052-6055. [CrossRef] [PubMed]

3. Lebreton, L.C.M.; van der Zwet, J.; Damsteeg, J.-W.; Slat, B.; Andrady, A.; Reisser, J. River plastic emissions to the world's oceans. Nat. Commun. 2017, 8, 15611. [CrossRef] [PubMed]

4. Mahler, G.J.; Esch, M.B.; Tako, E.; Southard, T.L.; Archer, S.D.; Glahn, R.P.; Shuler, M.L. Oral exposure to polystyrene nanoparticles affects iron absorption. Nat. Nanotechnol. 2012, 7, 264-271. [CrossRef]

5. Windsor, F.M.; Tilley, R.M.; Tyler, C.R.; Ormerod, S.J. Microplastic ingestion by riverine macroinvertebrates. Sci. Total Environ. 2019, 646, 68-74. [CrossRef]

6. Wójcik-Fudalewska, D.; Normant-Saremba, M.; Anastácio, P. Occurrence of plastic debris in the stomach of the invasive crab Eriocheir sinensis. Mar. Pollut. Bull. 2016, 113, 306-311. [CrossRef]

7. Song, Y.K.; Hong, S.H.; Jang, M.; Han, G.M.; Jung, S.W.; Shim, W.J. Combined Effects of UV Exposure Duration and Mechanical Abrasion on Microplastic Fragmentation by Polymer Type. Environ. Sci. Technol. 2017, 51, 4368-4376. [CrossRef]

8. Song, Y.K.; Hong, S.H.; Jang, M.; Han, G.M.; Jung, S.W.; Shim, W.J. Corrections to “Combined Effects of UV Exposure Duration and Mechanical Abrasion on Microplastic Fragmentation by Polymer Type". Environ. Sci. Technol. 2018, 52, 3831-3832. [CrossRef] 
9. Ter Halle, A.; Ladirat, L.; Gendre, X.; Goudouneche, D.; Pusineri, C.; Routaboul, C.; Tenailleau, C.; Duployer, B.; Perez, E. Understanding the Fragmentation Pattern of Marine Plastic Debris. Environ. Sci. Technol. 2016, 50, 5668-5675. [CrossRef]

10. Setälä, O.; Fleming-Lehtinen, V.; Lehtiniemi, M. Ingestion and transfer of microplastics in the planktonic food web. Environ. Pollut. 2014, 185, 77-83. [CrossRef]

11. Shen, M.; Zhang, Y.; Zhu, Y.; Song, B.; Zeng, G.; Hu, D.; Wen, X.; Ren, X. Recent advances in toxicological research of nanoplastics in the environment: A review. Environ. Pollut. 2019, 252, 511-521. [CrossRef] [PubMed]

12. Paul-Pont, I.; Lacroix, C.; González Fernández, C.; Hégaret, H.; Lambert, C.; Le Goïc, N.; Frère, L.; Cassone, A.-L.; Sussarellu, R.; Fabioux, C.; et al. Exposure of marine mussels Mytilus spp. to polystyrene microplastics: Toxicity and influence on fluoranthene bioaccumulation. Environ. Pollut. 2016, 216, 724-737. [CrossRef] [PubMed]

13. Lei, L.; Wu, S.; Lu, S.; Liu, M.; Song, Y.; Fu, Z.; Shi, H.; Raley-Susman, K.M.; He, D. Microplastic particles cause intestinal damage and other adverse effects in zebrafish Danio rerio and nematode Caenorhabditis elegans. Sci. Total Environ. 2018, 619-620, 1-8. [CrossRef] [PubMed]

14. Wang, M.; Wang, X.; Luo, X.; Zheng, H. Short-term toxicity of polystryrene microplastics on mysid shrimps Neomysis japonica. IOP Conf. Ser. Earth Environ. Sci. 2017, 61, 012136. [CrossRef]

15. Almeida, M.; Martins, M.A.; Soares, A.M.V.; Cuesta, A.; Oliveira, M. Polystyrene nanoplastics alter the cytotoxicity of human pharmaceuticals on marine fish cell lines. Environ. Toxicol. Pharmacol. 2019, 69, 57-65. [CrossRef] [PubMed]

16. Yin, L.; Liu, H.; Cui, H.; Chen, B.; Li, L.; Wu, F. Impacts of polystyrene microplastics on the behavior and metabolism in a marine demersal teleost, black rockfish (Sebastes schlegelii). J. Hazard. Mater. 2019, 380, 120861. [CrossRef]

17. Collard, F.; Gilbert, B.; Compère, P.; Eppe, G.; Das, K.; Jauniaux, T.; Parmentier, E. Microplastics in livers of European anchovies (Engraulis encrasicolus, L.). Environ. Pollut. 2017, 229, 1000-1005. [CrossRef]

18. Da Silva, E.; Kembouche, Y.; Tegner, U.; Baun, A.; Jensen, K.A. Interaction of biologically relevant proteins with $\mathrm{ZnO}$ nanomaterials: A confounding factor for in vitro toxicity endpoints. Toxicol. In Vitro 2019, 56, 41-51. [CrossRef]

19. Hermsen, E.; Mintenig, S.M.; Besseling, E.; Koelmans, A.A. Quality Criteria for the Analysis of Microplastic in Biota Samples: A Critical Review. Environ. Sci. Technol. 2018, 52, 10230-10240. [CrossRef]

20. Naik, R.K.; Naik, M.M.; D'Costa, P.M.; Shaikh, F. Microplastics in ballast water as an emerging source and vector for harmful chemicals, antibiotics, metals, bacterial pathogens and HAB species: A potential risk to the marine environment and human health. Mar. Pollut. Bull. 2019, 149, 110525. [CrossRef]

21. Prata, J.C.; da Costa, J.P.; Lopes, I.; Duarte, A.C.; Rocha-Santos, T. Environmental exposure to microplastics: An overview on possible human health effects. Sci. Total Environ. 2020, 702, 134455. [CrossRef] [PubMed]

22. Bouwmeester, H.; Hollman, P.C.H.; Peters, R.J.B. Potential Health Impact of Environmentally Released Microand Nanoplastics in the Human Food Production Chain: Experiences from Nanotoxicology. Environ. Sci. Technol. 2015, 49, 8932-8947. [CrossRef] [PubMed]

23. Xu, B.; Liu, F.; Brookes, P.C.; Xu, J. Microplastics play a minor role in tetracycline sorption in the presence of dissolved organic matter. Environ. Pollut. 2018, 240, 87-94. [CrossRef] [PubMed]

24. Guo, X.; Wang, J. Sorption of antibiotics onto aged microplastics in freshwater and seawater. Mar. Pollut. Bull. 2019, 149, 110511. [CrossRef]

25. Bakir, A.; O'Connor, I.A.; Rowland, S.J.; Hendriks, A.J.; Thompson, R.C. Relative importance of microplastics as a pathway for the transfer of hydrophobic organic chemicals to marine life. Environ. Pollut. 2016, 219, 56-65. [CrossRef]

26. Rist, S.; Carney Almroth, B.; Hartmann, N.B.; Karlsson, T.M. A critical perspective on early communications concerning human health aspects of microplastics. Sci. Total Environ. 2018, 626, 720-726. [CrossRef]

27. Alimi, O.S.; Farner Budarz, J.; Hernandez, L.M.; Tufenkji, N. Microplastics and Nanoplastics in Aquatic Environments: Aggregation, Deposition, and Enhanced Contaminant Transport. Environ. Sci. Technol. 2018, 52, 1704-1724. [CrossRef]

28. Heinrich, P.; Braunbeck, T. Bioavailability of microplastic-bound pollutants in vitro: The role of adsorbate lipophilicity and surfactants. Comp. Biochem. Physiol. Part C Toxicol. Pharmacol. 2019, 221, 59-67. [CrossRef] 
29. Godoy, V.; Blázquez, G.; Calero, M.; Quesada, L.; Martín-Lara, M.A. The potential of microplastics as carriers of metals. Environ. Pollut. 2019, 255, 113363. [CrossRef]

30. Thorsten, H.; Maren, W.; Thilo, H. Effect of aging on adsorption behavior of polystyrene microplastics for pharmaceuticals: Adsorption mechanism and role of aging intermediates. J. Hazard. Mater. 2020, 384, 121193.

31. Tian, W.; Songhua, L.; Wen, C.; Jiehui, R.; Min, W.; Baowei, H.; Ziyi, J.; Ying, L.; Yubing, S. A spectroscopic and theoretical investigation of interaction mechanisms of tetracycline and polystyrene nanospheres under different conditions. Environ. Pollut. 2019, 249, 398-405.

32. Hernandez, L.M.; Yousefi, N.; Tufenkji, N. Are There Nanoplastics in Your Personal Care Products? Environ. Sci. Technol. Lett. 2017, 4, 280-285. [CrossRef]

33. Nandiyanto, A.B.D.; Suhendi, A.; Ogi, T.; Iwaki, T.; Okuyama, K. Synthesis of additive-free cationic polystyrene particles with controllable size for hollow template applications. Colloids Surf. A Physicochem. Eng. Asp. 2012, 396, 96-105. [CrossRef]

34. Nandiyanto, A.B.D.; Kim, S.-G.; Iskandar, F.; Okuyama, K. Synthesis of spherical mesoporous silica nanoparticles with nanometer-size controllable pores and outer diameters. Microporous Mesoporous Mater. 2009, 120, 447-453. [CrossRef]

35. Hans, S.; Flemming, I.; Richard, A.B.; Bent, H.-S.; Jim, K.B.; Christian, J.W.; David, J.J.; Keith, R.S. Dissipation of oxytetracycline, chlortetracycline, tetracycline and doxycycline using HPLC-UV and LC/MS/MS under aquatic semi-field microcosm conditions. Chemosphere 2005, 60, 619-629.

36. Juling, S.; Niedzwiecka, A.; Böhmert, L.; Lichtenstein, D.; Selve, S.; Braeuning, A.; Thünemann, A.F.; Krause, E.; Lampen, A. Protein Corona Analysis of Silver Nanoparticles Links to Their Cellular Effects. J. Proteome Res. 2017, 16, 4020-4034. [CrossRef]

37. Guo, X.; Chen, C.; Wang, J. Sorption of sulfamethoxazole onto six types of microplastics. Chemosphere 2019, 228, 300-308. [CrossRef]

38. Wu, B.; Wu, X.; Liu, S.; Wang, Z.; Chen, L. Size-dependent effects of polystyrene microplastics on cytotoxicity and efflux pump inhibition in human Caco-2 cells. Chemosphere 2019, 221, 333-334. [CrossRef]

39. Shin, N.R.; Whon, T.W.; Bae, J.W. Proteobacteria: Microbial signature of dysbiosis in gut microbiota. Trends Biotechnol. 2015, 33, 496-503. [CrossRef]

40. Ma, Y.; Huang, A.; Cao, S.; Yi, M.; An, H.; Si, C.; Fei, S.; Lian, W.; Hong, G.; Rong, J. Effects of nanoplastics and microplastics on toxicity, bioaccumulation, and environmental fate of phenanthrene in fresh water. Environ. Pollut. 2016, 219, 166-173. [CrossRef]

41. Qiao, R.; Sheng, C.; Lu, Y.; Zhang, Y.; Ren, H.; Lemos, B. Microplastics induce intestinal inflammation, oxidative stress, and disorders of metabolome and microbiome in zebrafish. Sci. Total Environ. 2019, 662, 246-253. [CrossRef] [PubMed]

42. Piloni, A.; Wong, C.K.; Chen, F.; Lord, M.; Walther, A.; Stenzel, H. Surface roughness influences the protein corona formation of glycosylated nanoparticles and alter their cellular uptake. Nanoscale 2019, 11, 23259-23267. [CrossRef] [PubMed]

(C) 2020 by the authors. Licensee MDPI, Basel, Switzerland. This article is an open access article distributed under the terms and conditions of the Creative Commons Attribution (CC BY) license (http://creativecommons.org/licenses/by/4.0/). 